DOI: $110.2478 /$ ausp-2018-0008

\title{
Gabriella Pusztai and Zsuzsanna Márkus, eds. 2017. Hungarian in the Motherland: Schools and Students beyond the Borders
}

Debrecen: Debrecen University Press. 334 pp. ${ }^{1}$

\author{
Review by \\ Erzsébet DANI \\ University of Debrecen (Hungary) \\ Faculty of Informatics, Department of Computer Science and LIS \\ erzsebet.dani@gmail.com
}

Hungarian in the Motherland: Schools and Students beyond the Borders is the second volume in the series Education in the $21^{\text {st }}$ Century. The collection of studies contains nineteen extensive writings by twenty-three authors; the focus is, as the title indicates very informatively, schools beyond the borders, Hungarian language and education. Eight institutions beyond the borders of Hungary (the Emanuel University of Oradea, the Sapientia Hungarian University of Transylvania, the University of Novi Sad, the Romanian Ministry of Education, the Hungarian Academy of Sciences, the Ferenc Rákóczi II. Transcarpathian Hungarian Institute, the Babeş-Bolyai University, the Regional Scientific Society of Subotica) are represented by twelve authors, while the work of eleven researchers from four Hungarian institutions (the University of Debrecen, the Eötvös Loránd University, the Eszterházy Károly University, and the Center for Social Sciences of the Hungarian Academy of Sciences) are welcome additions to the list of authors.

In the four big regions beyond the border (Transcarpathia, Transylvania, Upper Hungary and Vojvodina) it is well known that the matter of Hungarian-language education is an extremely complex issue. Hungarian in the Motherland highlights this complexity of Hungarian language usage and education. Naturally, the issue is always embedded in the entire (majority) educational system of the studied Carpathian Basin countries. As we learn from the Preface, the result of the struggle of minority Hungarian communities for Hungarian educational institutions, in the past two and a half decades, has been a vertical and horizontal expansion of those institutional systems. This process is not only a "minority social aspiration

1 This review was published in Hungarian in Debreceni Szemle vol. 26, no. 1 (2018): 96-102. 
motivated by internal driving forces" $(7),{ }^{2}$ but also reflects the possibilities of the current educational policies of the studied countries. The latter can help in some educational policy situations, while in some other educational environments it may hinder the right to be educated in the minority's native language.

The expansion of the educational systems started in the relevant countries with the tremendous social changes of 1989-90, almost simultaneously and dynamically. The results, however, differ in the examined regions, depending on the current educational policy of the majority culture, i.e. on how it relates to minority rights. The author-researchers of the volume attempted to paint a complete, multi-faceted picture. The four countries with significant Hungarian minorities (Ukraine, Romania, Slovakia, Serbia) have different educational policies and minority rights management, but all schools beyond the borders agree that the four majority societies prefer the coercive method of assimilation and differ only in the manner in which they apply the method. These coercive methods are particularly effective within schools.

The volume consists of three main parts ("chapters"), and in each, the issues are addressed according to three different criteria:

(1) the child is the most important for education (and there is a drastic reduction in this field);

(2) the mother tongue has a prominent role; ecclesiastical engagement is particularly important;

(3) identity preservation is a priority as the identity-forming function of the school is crucial in minority existence.

These goals are not simply declarations in the book. We get a cross-sectional view of the present, and beyond - the authors also try to explore the historical roots of these complex interrelationships and to imagine the future consequences as well. Most of the studies are based on empirical surveys or statistical analysis, but some approach the subject of mother tongue education from an educational policy (socio-political) perspective.

The three major parts of the volume - On the Balance Sheet; Talent and Responsibility; New Paths - indicate the evolution of thought in the book as a whole. The first large unit (On the Balance Sheet) provides a comprehensive assessment of the educational situation of Hungarian communities across the borders, and focuses primarily on the interrelationship between the availability of, versus demand for, those institutions. The Talent and Responsibility section contains studies based typically on empirical analysis, focusing on the roles and possibilities of the studied Carpathian-Basin institutions of higher education. The third part (New Paths) puts under a magnifying glass the current challenges of the region's dynamically changing educational systems.

2 All page numbers with no further bibliographical information refer to the work reviewed. 
The strengths of the volume are the absence of disturbing overlaps, a multifaceted approach, and a multitude of viewpoints which make the flow of thoughts dynamic. The book provides a comprehensive picture of Hungarian education in the four regions. The present review will proceed from region to region. Nine studies are dedicated to the Partium (a region in Romania right beyond the Hungarian border) and the Transylvanian situation. Regrettably, Vojvodina and Upper Hungary are represented by only one (true, highly valuable and informative) contribution. It is good to see the emphatic presence of Transcarpathia with five studies, discussing the educational situation on a broad scale, as Transcarpathian Hungarians may be the smallest in number in relation to the total figure of Hungarians beyond the borders of Hungary. (A 2001 census informs us that Hungarians number 156,000 in Ukraine, most of them in Transcarpathia.) It is a welcome fact because the number of studies devoted to a region cannot be expected to be proportionate to the numbers of minority presence there. In the case of Partium and Transylvania, where the largest number of Hungarians live (according to the data of the Romanian 2011 census, 1,227,623 citizens of Hungarian nationality live in Romania), the number of studies is proportionate. But the Hungarians of Upper Hungary and Vojvodina are underrepresented (in Slovakia, also according to 2011 official census data, 458,467 citizens declared themselves Hungarians; the number of Hungarians in Serbia/Vojvodina was 251,136 in 2011). The issue that each region beyond the border has a slow but continuous demographic decline is highlighted by each study. In what follows, the individual chapters of Hungarian in the Motherland will be reviewed by grouping them according to the regions they relate to.

\section{Transylvania and Partium (Romania)}

The primary concern of these writings is the region's Hungarian higher education. József Pálfi's university history ("Twenty-five Years and What Is behind It") presents the milestones of the Partium Christian University, including the presence of Christian faith and morality in the mission statement. Gábor Flóra's work is also related to this institution and to ecclesiastical responsibility ("Ecclesiastic Responsibility and Higher Education Institutional Identity in a Minority Situation"). It focuses on Christian identity, where the assertion of Christian values is one of the central goals, and stresses the ecumenical openness of the "school surrounded with churches" (231). Flóra also emphasizes the issue of human resources: the University of Debrecen has played and is still playing a key role in this regard, although it is now more able to develop the institution's own human resources. Partium is represented by another especially interesting research: Krisztina Bernáth (in "Student Attitudes in Higher Education 
Institutions of the Partium Region") presents a qualitative questionnaire-based cross-sectional research carried out in the HERD project, in which the attitudes of higher education students were assessed. It is a very exciting topic, and identifying factors of learning attitudes could provide guidance for planning the education of the future.

The presentation of Transylvanian higher education situation is further refined by the studies pertaining to the Babeş-Bolyai University, Cluj-Napoca. The studies by Noémi Szabó-Thalmeiner and Gabriella Mária Stark - "Education at Higher Level, or Higher-Education Training of Kindergarten Teachers and School Teachers at the Babeş-Bolyai University" and "PADI Student-Pedagogues," respectively - deal with the multi-phase research of the Babeş-Bolyai University's Pedagogical and Applied Didactics Institute (PADI) as well as that of its Faculty of Psychology and Education, from post-secondary to higher education levels, at four locations. Contrary to expectations, both works report on positive results, as the pedagogical vocation is a favoured choice at the examined sites. However, despite the positive conclusion, the reader still has a sense of lack of closure: the summaries are too general in nature, do not go beyond the presentation of results, and do not suggest possibilities for improving the situation.

In "Unequal Opportunities in Education for Hungarians from Romania and the Expansion of Higher Education as Reflected by Censuses" Valér Veres deals with the expansion of Hungarian higher education in Transylvania. Analyzing recent census data and the sources of the National Statistical Institute, he models a specific Hungarian-language higher education, also using visual techniques to illustrate the Transylvanian situation. He focuses on the Hungarian identityshaping function of education, which can only work if it takes place in the mother tongue. Veres objectively concludes that although Hungarian student enrolment is gradually increasing, the inequalities of opportunity do remain unchanged in the Romanian-Hungarian relation, even though the political struggles of the Hungarian minorities have not been in vain.

In addition to the specific issues of higher education, the status of Hungarian public education in Transylvania is also highlighted: first in a general context; second, as an impact of the reforms related to preparatory classes; and thirdly, in the context of vocational training. László Murvai's "Some Features of Transylvanian Hungarian Education" discusses some of the peculiarities of Hungarian public education in Transylvania in the context of legislation, school network and enrolment indicators as well as with respect to content-related aspects of educational organization. Historical embedding is immensely broad. Murvai does not simply explore the current situation, but, beginning with the period that followed the Treaty of Trianon, he outlines the regulation of minority education, the "socialist" transformation of public education (and its impact on the Hungarian minority), and the legislation practices that came with the post- 
1989 social changes. Transylvanian Hungarian public education is clearly visible in his detailed statistics. The tone is essentially objective, with some covert but realistic questions posed (with presupposed answers) here and there, but always in a manner suggestive of the (Ionesco-like) tragi-comedy of the situation.

Szeklerland, a unique block of Hungarians in Transylvania, rates an independent treatment thanks to Kinga Magdolna Mandel's "Direct and Indirect Effects of the Preparatory-Class Reforms in Szeklerland." In a very colorful, sometimes outright humorous style, Mandel propounds the issue, concluding it with an innovative summary. The matter of vocational training is a particularly vital issue for the Transylvanian region. Juliánnna Bodó and Zoltán A. Bíró’s multi-faceted, objective study argues for maintaining the minority nature of vocational training (“Changing Hungarian Vocational Training in Romania”). No matter how detailed, this writing merely focuses descriptively on the situation and does not formulate a conclusion.

\section{Transcarpathia (Ukraine)}

It is remarkable for the volume to describe several levels of the Transcarpathian education system, from kindergarten to doctoral training. Two studies focus on education and language policy in general. Ildikó Orosz tries to follow Ukraine's two-and-a-half decades of often unfollowable educational policy boldly, critically and unapologetically ("On the Situation and Quality of Transcarpathian Hungarian-Language Education”). She introduces the differences arising from the Transcarpathian situation: multiple border changes in the past, political discrimination, collective guilt, the development of the Ukrainian nation state and the strengthening of Ukrainian identity. She emphasizes the polemics of mothertongue education and clearly sums up her finding that in Ukraine the Transcarpathian Hungarians are undoubtedly the defeated segment of the population. She levels unbiased criticism at the quality of education, supported by interviews. As for the future, she provides ideas for innovative thinking. It would be desirable for competent Ukrainian educational policy makers to dip into her study.

Krisztina Pecsora ("The Impact of Ukrainian Language Policy on Hungarian Public Education in Transcarpathia”) presents a painful picture of the Hungarian students in Transcarpathia. The Hungarian student with a minority status has three options: integration (bilingualism), assimilation (monolingualism $=$ state language) or segregation (monolinguality $=$ mother tongue). All aspects of the study confront us with the violent assimilation drive of the Ukrainian language policy. We must pay close attention to the factual and scientific chapters of Hungarian in the Motherland, especially to those concerned with current educational policy events in Ukraine. Attila Z. Papp focuses on the motivations of Transcarpathian 
Ph.D. students ("What Motivates Transcarpathian Students in Deciding on Doctoral Training: An Attempted Typology”). By means of semi-structured interviews, he presents types of student pathways with background analysis and features interesting typologies. The essence of the term "Scientific Patriotism" is that their minority origin has become dominant for these $\mathrm{PhD}$ students. Coauthors Anita Nánási-Molnár and Magdolna Séra deal with kindergarten and school choice motivators ("Kindergarten and School Choice Motivators in Transcarpathia"); re-analyzing available statistical data, they demonstrate the connection between the language of teaching and identity, as well as statistically significant correlations between ethnic identity and the quality of the Hungarian kindergartens and schools. Mihály Fónai and Katalin Cséke’s decision to study the Transcarpathian Roma, "the minority of minorities," is unusual and praiseworthy ("Situation Report on the Schooling of the Transcarpathian Hungarian-Speaking Romas"). Relying on scholarly research results, they emphasize religion as being the decisive factor in the development of Roma youth. Religion contributes to self-acceptance, change of worldview, and by transforming outlooks it creates a marginal identity. Fónai and Cséke also pay attention to the various, relevant organizations and foundations, incorporating tables and photographic material to illustrate the significant work those organizations and foundations do.

\section{Vojvodina (Serbia)}

The educational situation of the Hungarians in Serbia is represented by a single, extremely valuable study in the volume. Irén Gábrity Molnár's work places the Hungarians from Vojvodina in the Serbian educational space, studies equal opportunities, student migration, and labour market expectations, also giving an account of the employment opportunities of minority professionals, using empirical research findings ("Educational Levels in Vojvodina: A Survey"). Through detailed statistical analysis, Gábrity Molnár explores the situation from kindergarten and primary school to higher education, highlighting the fact that there is no independent Hungarian university in Serbia. It is a great plus for the study that, besides the situational analysis, it also provides concrete suggestions that could serve as a useful guide for educational policy makers and organizers.

\section{Upper Hungary (Slovakia)}

The Hungarian secondary schools and their graduating students in Slovakia (especially Central-Eastern Slovakia) are also covered in a single study, by Tünde Morvai ("School-Leavers of Central-Eastern-Slovakian Hungarian-Language 
Secondary Schools"). Her quantitative and qualitative research results indicate that broadening offers in Hungarian-language higher-education training led to a drop of interest for study in Hungary. The eastern higher education region of Kosice and Eperjes is becoming more and more attractive for students. Despite deteriorating demographic numbers, the student body seems to be growing, and this can be considered a positive finding. However, the necessity of state-language knowledge is an important factor in school choices here as well.

\section{The Broader Perspective (Europe, the Carpathian Basin)}

The regional structure of this collection of essays is further refined by the research results of two comprehensive studies that deal with minority European higher education, with a broader European and Carpathian Basin perspective. Zoltán Takács ("The Higher Education of Minorities and New Higher-Education Institutions in Europe and in the Carpathian Basin") examines minority education in a European context, from consolidational, reformist-alternative and educational policy perspectives (with special regard to Eastern Europe). His chapters on institutional history as well as the recounting and analysis of the conditions set by local society and political will as requirements for founding institutions conclude that minorities are underrepresented in higher education, not only worldwide, but also in Europe. Takács stresses the point, however, that universities are among the most important instruments of nation building. If we take this as our point of departure, we may surmise that underrepresentation may not be a coincidence.

Gabriella Pusztai and Zsuzsanna Márkus's broad and comprehensive contribution ("Hungarian Students in the Higher Education Institutions of the Carpathain Basin") shares the findings of a research program launched at the University of Debrecen at the turn of the millennium. The project started with empirical research on education in the mother country and across borders (with fieldwork, quantitative data collection) and became more and more extensive as it progressed (thirteen higher education institutions, $\approx 1750$ students). The basic question they posed themselves was: is it possible to identify a feature in the status of Hungarian minorities (both uniform and diverging from what we find in Hungary) which would be common enough to allow young people participating in Hungarian-speaking educational institutions beyond the borders to be considered a single group? The results exhibit a varied picture. What is more, serious differences among Hungarian minorities were exposed, with proportional and socio-demographic dissimilitudes, and differences in settlement structure and language usage. One of the merits of this research is that it is based on John Ogbu's cultural-ecological theory, which distinguishes immigrants seeking assimilation 
from indigenous minorities interested in preserving their identity. In this way, the researchers made it clear: the Hungarian population of the Carpathian Basin is an indigenous minority, therefore the right to use the mother tongue is their right everywhere, regardless of national boundaries and majority languages.

Conversely, the volume reveals that the education of each country defines and applies minority rights differently. It all boils down to dual, opposite cultural assimilation spirals. From the Hungarian viewpoint the direction of the spiral is downward (opportunities are continuously narrowed); from the viewpoint of the majority culture it is an upward spiral (as a result of assimilation pressures).

In an essay that does not fit the regional organization of the book, Károly Gergely Bán investigates the teaching methodology of geography between the two World Wars from an unusual perspective, which was timely in those days. He discusses how the contents of the curriculum, the textbook presentation and the teaching methods of geography as a subject were transformed by the Trianon trauma ("The Intrusion of Trianon into the Secondary-School Teaching of Geography in the Interwar Period”).

\section{Summary}

As a summary, it can be concluded that Hungarian in the Motherland is an excellent work that professionals and interested readers alike can benefit from. There is good cohesion within the individual chapters, and the scientific reference system as well as the referenced bibliography are impressive. The successive, complementary, and interlinked studies sweep the reader along. The most important scientific achievement of this collection of studies is the formation of collaborative scientific workshops. In the light of these analytical investigations, cross-border dialogue has intensified on this topic - a development which generally augurs well as for future research of the subject. 